* Corresponding author

E-mail address:z.pater@pollub.pl (P.Zbigniew)

Article information

Article history: AMS-Volume15-No.2-00108-11

Received 28 February 2011

Accepted 12 May 2011

Available online 26 August

\section{A FEM Analysis of Cross-Wedge Rolling of Toothed Shafts}

\author{
Zbigniew Pater a* \\ a Lublin University of Technology, 36 Nadbystrzycka, 20-618 Lublin, Poland
}

\section{KEY WORDS}

Cross Rolling, Toothed Shaft, FEM, Experiment

\begin{abstract}
This paper presents a new concept for forming toothed shafts based on the cross-wedge rolling process (CWR). This method consists in using special inserts in the shape of flat rack bars, which, acting on a billet, extrude material from tooth spaces to tooth points. These inserts are placed at the finish end of a wedge tool. Numerical calculations (based on FEM) and experimental rolling tests unequivocally demonstrate the effectiveness of the proposed method for forming spur (straight-cut), helical, curved and herringbone gear teeth.
\end{abstract}

\section{Introduction}

Toothed rims can be effectively manufactured by means of metal forming methods. Among the methods used for metal forming of gear teeth, forging and rolling are of greatest significance (Lange et al., 1985). Both of these methods started to be used for forming gear rims as early as in the 19th century. However, it was not until the 1950's that serious development of metal forming of toothed wheels began. It should be noticed that the forming of gear teeth is usually a separate forging operation and requires the use of special machines and tools. Manufacturing effectiveness can be increased by limiting the number of the applied operations, which results in shorter production time, reduced number of machines used and lower manufacturing costs.

One of the most often used products in the automotive industry are stepped shafts with toothed rims. Parts of this type are manufactured by machining from die forgings. This manufacturing method, however, can be modernized by combining the operations of metal forming of shaft and gear teeth. For that purpose, the cross-wedge rolling method (CWR), successfully applied in the manufacturing of stepped axles and shafts (Holub, 1963; Fu, et al., 1993; Pater, 1998), can be used. The wedge tools should then be equipped with special inserts enabling tooth forming. This paper presents the results of numerical and experimental analyses of hot rolling of spur, helical, curved and herringbone gear teeth. Forming of teeth with flat rack bars was proposed. Such a solution is optimal in regard of the potential implementation costs (tool manufacturing) and follows from the wide application in industry of wedge rolling mills with flat tools.

\section{Numerical analysis}

A series of FEM numerical simulations were carried out to check the possibility of forming of gear teeth by cross-wedge rolling. It was assumed that the forming process occurs 
without elongation of rolled parts in the longitudinal (axial) direction. This means that at the tool designing stage, the cross sectional areas of the toothed step and billet should be equal.

Considering the above-mentioned remarks, a gear tooth-forming principle was analyzed which resembles the one used in the well-known process of cold rolling with flat rack bars (the Roto-Flo method). However, unlike the latter method, the analyzed process is carried out in hot conditions, with shorter tools and without supporting the rolled parts on both sides in guiding devices.

\subsection{Gear tooth-rolling}

In order to check the possibility of forming gear teeth by using the proposed method, the process was considered of forming a 1.5 module, 18-tooth gear rim on a shaft (at the length of $30 \mathrm{~mm}$ ). It was assumed that rolling would be performed using two flat-rack bars, moving in the opposite directions, with the parameters shown in Fig. 1. The working surface of the tools was divided into two parts: the forming part (inclined in the rolling direction at angle $\gamma$ ) and the sizing part with a constant tooth height. On the basis of initial numerical calculations (Pater, 2009) done at plane strain, it was found that the tool lead angle was $\gamma=0.5$. This is because at larger $\gamma$ values overlaps appear and the precision of tooth making decreases.

Simulations were made using commercial software DEFORM-3D. It was assumed in the calculations that the billet (steel C45) was heated to $1150^{\circ} \mathrm{C}$ and the tools had a constant temperature of $50^{\circ} \mathrm{C}$ during the process. The remaining parameters assumed in the calculations included tool velocity $\mathrm{v}=0.1 \mathrm{~m} / \mathrm{s}$, friction factor at the metal-tool interface $\mathrm{m}=0.8$, heat exchange coefficient between tool and material $-10 \mathrm{~kW} / \mathrm{m}^{2} \mathrm{~K}$, and heat exchange coefficient between material and environment $-0.2 \mathrm{~kW} / \mathrm{m}^{2} \mathrm{~K}$. A model of the material being formed was adopted from the library of the software used. All the analyzed cases of rolling adopted the same billet shape and dimensions, as specified in Fig. 2 , and the diameter of the billet step on which teeth were being formed was equal to the pitch diameter of the toothed wheel. Moreover, it was assumed that gear teeth would be formed using inserts (rack bars), which in a longitudinal section had a shape shown in Fig. 1. The inserts in all the analyzed cases had an identical width of $60 \mathrm{~mm}$. However, the way in which the teeth in the inserts were made changed, depending on the type of gear teeth being formed, in the following way:

- spur gear teeth - perpendicularly to the rolling direction (tool movement);

- curved gear teeth - at the radius $R 35$;

- helical gear teeth - at an angle of $60^{\circ}$ to the rolling direction, in accordance with Fig. 3;

- herringbone gear teeth - on both sides at an angle of $60^{\circ}$ to the rolling direction.

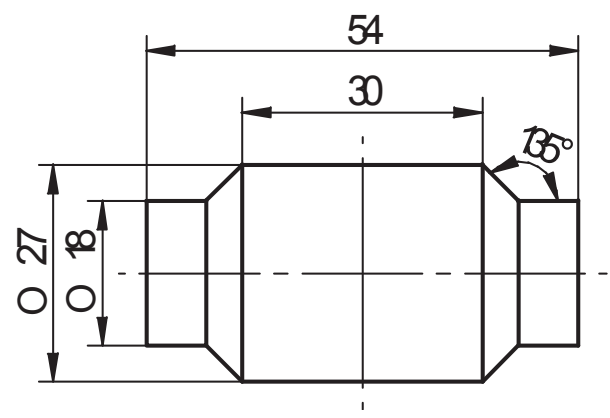

Fig. 2: A billet for the rolling of toothed rims considered in the numerical analysis.

Tools for all four cases of rolling were designed using Solid Edge CAD software. The tooth edges were rounded by a radius of $1.2 \mathrm{~mm}$ (at the beginning of the forming zone) to $0.3 \mathrm{~mm}$ (in the sizing zone). Next, they were imported to DEFORM-3D software, in which numerical simulations of the rolling process were made. One of the geometrical models used in the numerical calculations of the process of rolling helical gear teeth is shown in Fig. 4.

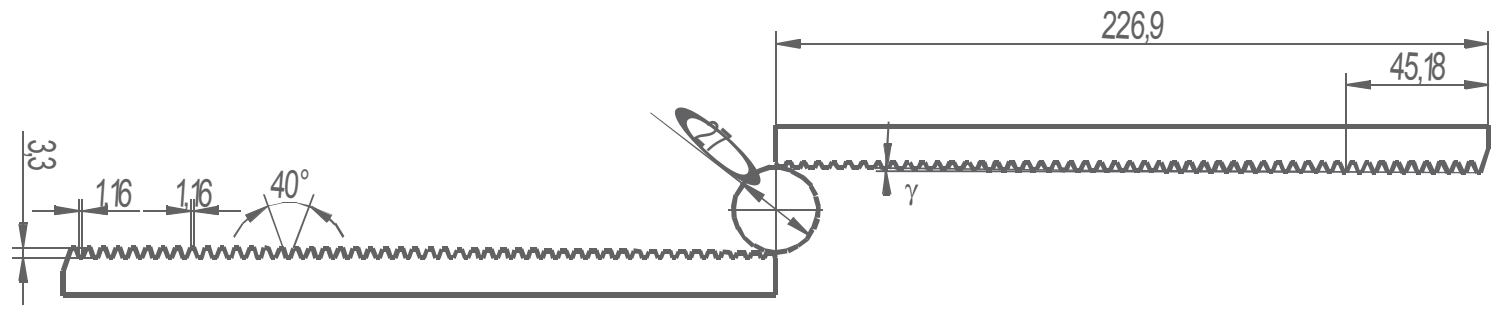

Fig. 1: A diagram of the gear tooth rolling process showing parameters adopted in the numerical calculations. 

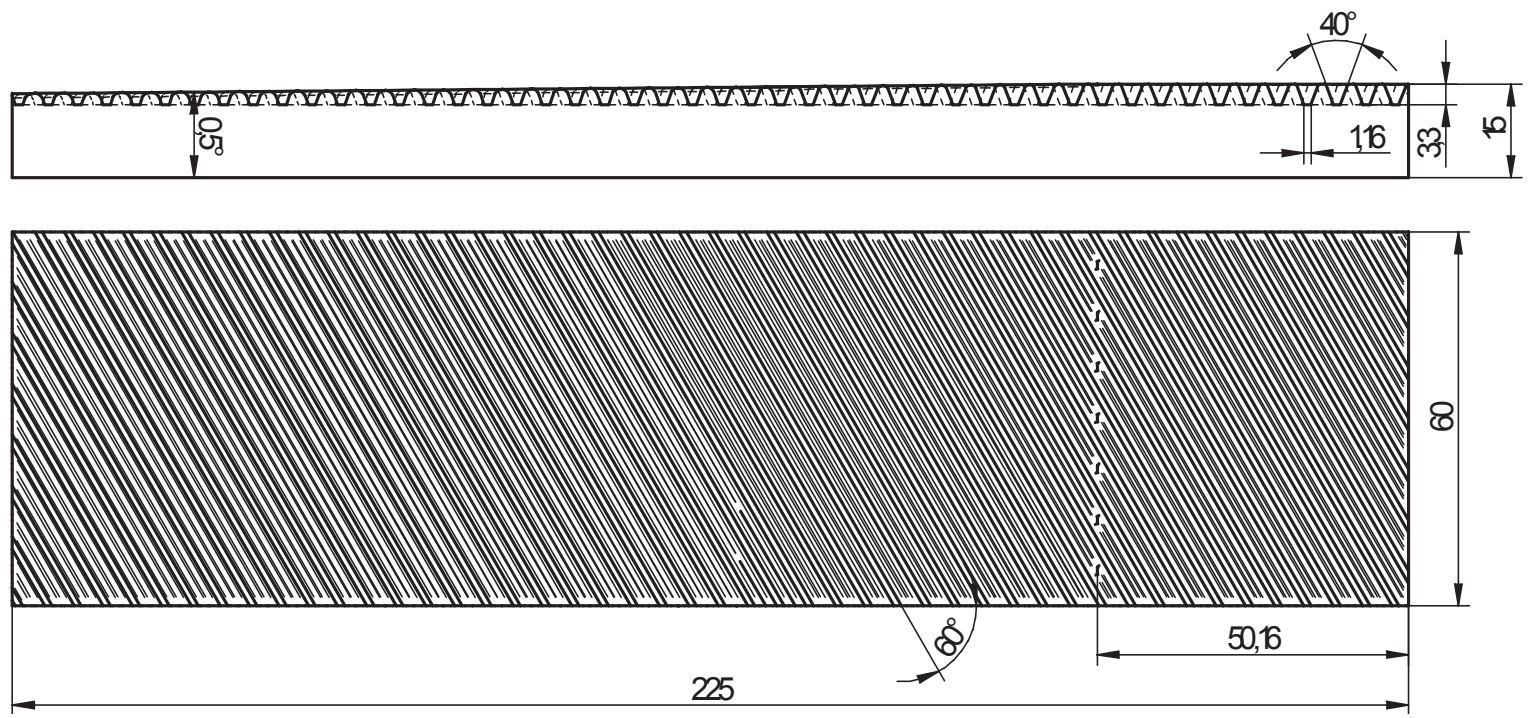

Fig. 3: A tool (rack bar) for the rolling of helical teeth with the most important parameters labeled.

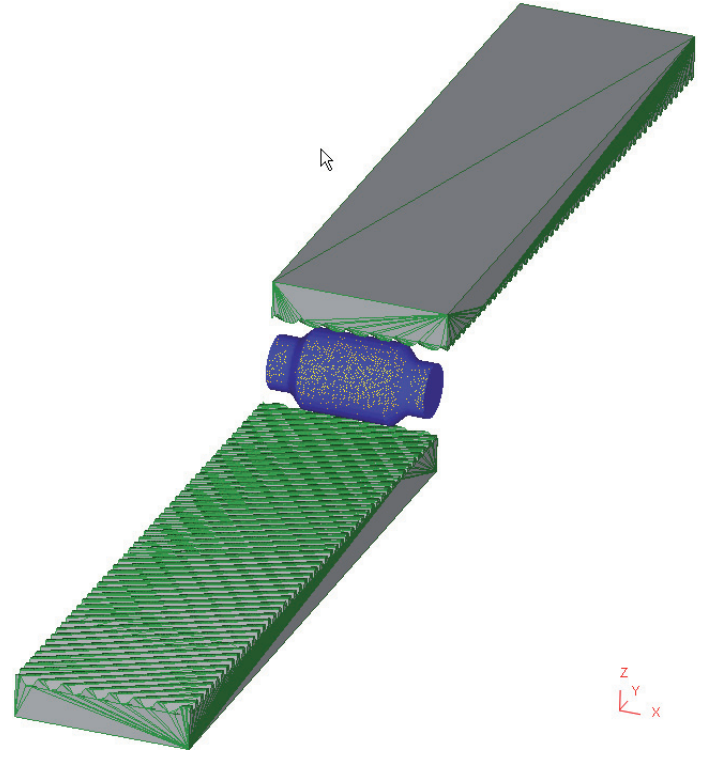

Fig. 4: A DEFORM-3D geometrical model of the process of rolling of helical teeth.

During calculations, the billet was modeled using 4-node tetragonal elements. Due to large changes in the shape of the workpiece during rolling, frequent remeshing was used in the calculations. The division of rolled parts into elements (at the final stage of the rolling process) is shown in Fig. 5. It follows from this figure that the largest concentration of elements occurred in the zone of the gear teeth being formed, which was characterized by the largest shape complexity.
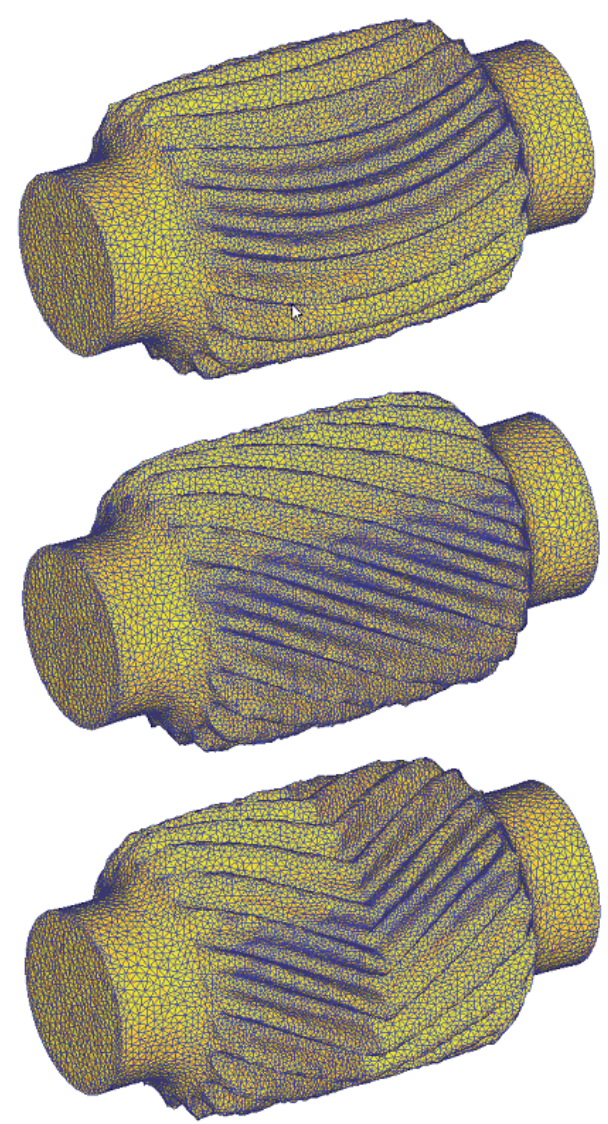

Fig. 4: The division of the part being formed into elements at the final stage of rolling, in which teeth are sized; starting from the top: curved, helical and herringbone gear teeth. 

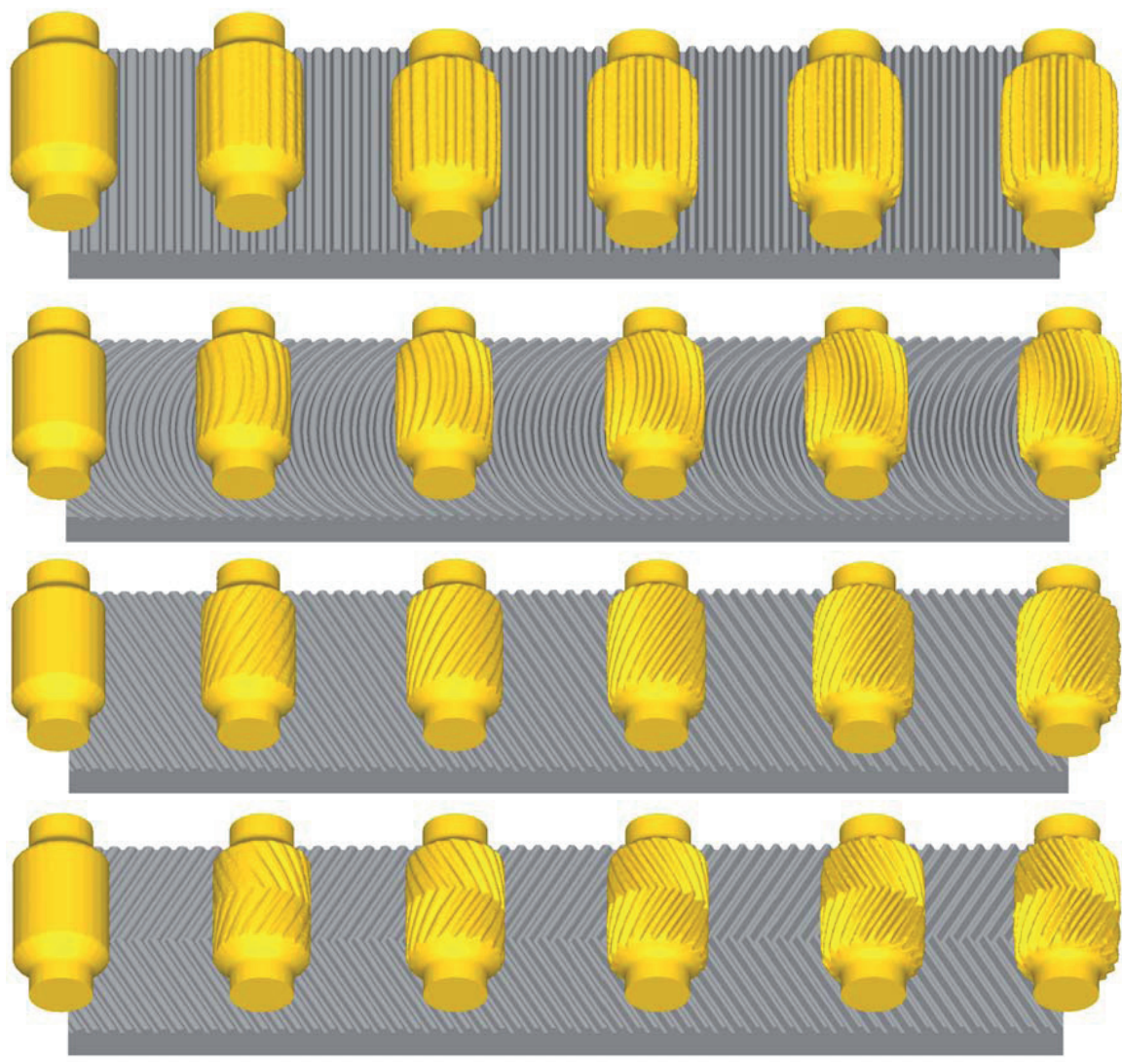

Fig. 6: Progression of the shape of the workpiece in the process of rolling of (starting from the top) spur, curved, helical and herringbone gear teeth.
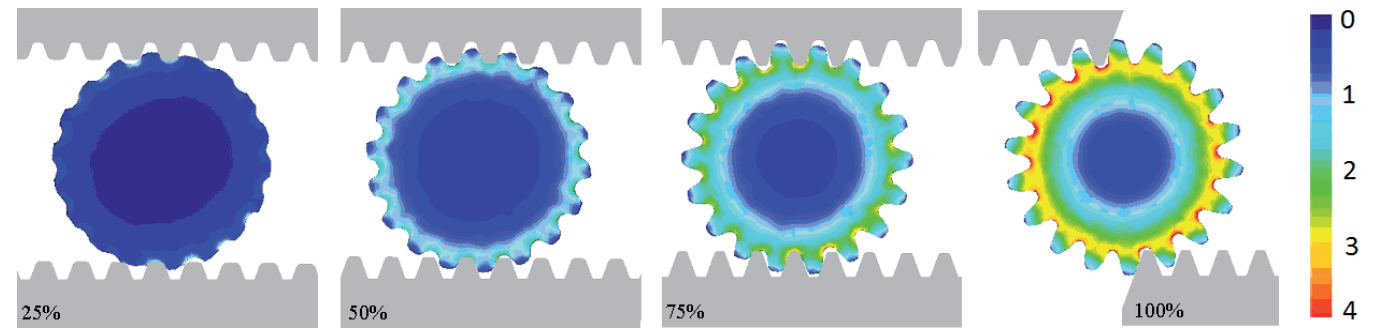

Fig. 7: Changes in the cross sectional shape of a workpiece in spur tooth rolling (with effective strain distribution indicated) dependent on the stage of the process.

The results of the numerical calculations enabled an analysis of changes in the shape of the workpiece during rolling. Shape progressions of the forgings determined using DEFORM-3D are compared in Fig. 6. It was found that in all the cases:

- tools gradually pressed into the billet extruding material from the tooth spaces to teeth;

- the length of the sizing zone had been appropriately chosen;

- the rolled parts assumed a proper, expected shape.
Numerical analysis done under 3D state of strain conditions confirmed that the gear teeth of the analyzed billets were formed as a result of surface flow of material (without elongation in the axial direction). Fig. 7 shows changes in effective strain in a cross section of a billet with straight-cut gear teeth, depending on the process stage. It was found that during gear tooth rolling, the metal underwent an intensive plastic working in the nearsurface layers, with a simultaneous lack of strain in the central (axial) area. The observed surface 
character of material flow did not depend on the type of the gear teeth being formed. In all the analyzed cases of rolling, the largest strains occurred in the spaces between the formed gear teeth. These strains were distributed concentrically and decreased in the direction of the axis of the part being formed, where they reached 0 . This can be observed well in Fig. 8, in which distributions of effective strain in cross sections of parts after rolling of curved and herringbone gear teeth are presented.

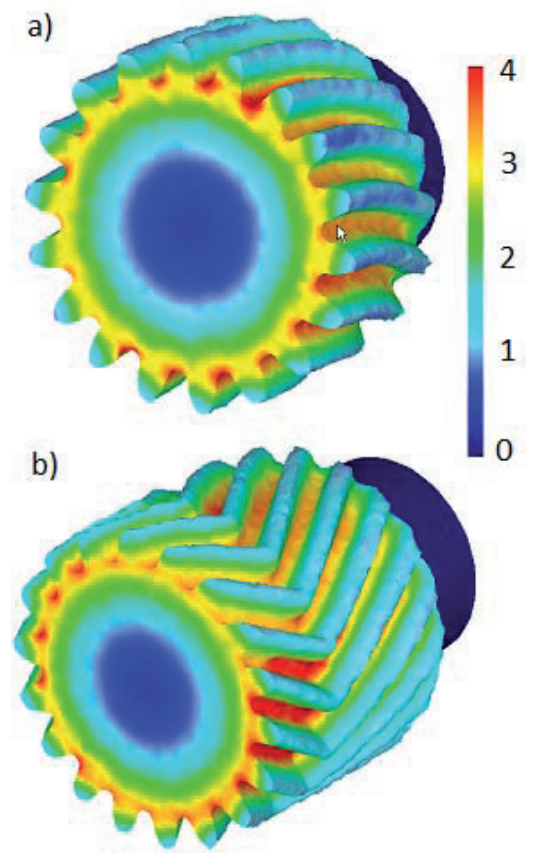

Fig. 8: Distribution of effective strain in a cross section of a rolled with a) curved and b) herringbone gear teeth.

The next Figure (Fig. 9) shows distributions of strain rate on the surface of workpieces (at the beginning of sizing). The data provided in this figure confirm that metal flows the most intensively in tooth spaces, from which it is extruded to tooth points. In the case of rolling straight-cut gear teeth, metal flow increases within the area of a single tooth. In all the other cases, however, it is distributed onto several neighboring teeth, which makes the forming process smoother.

Calculations were also made to determine the distribution of the damage criterion in the part after gear tooth rolling. It was found that the maximum values of this criterion were located in the area of the formed teeth (Fig. 10). However, these values were almost twice smaller than critical val-ues at which metal cracked.

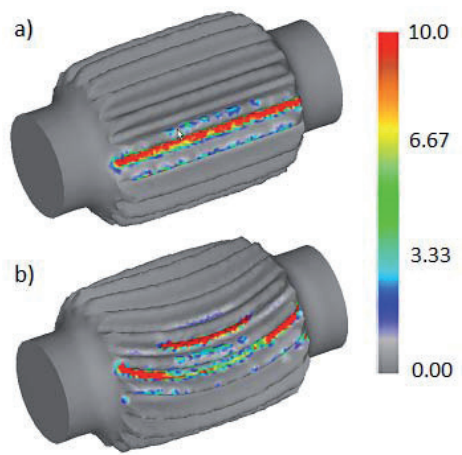

c)

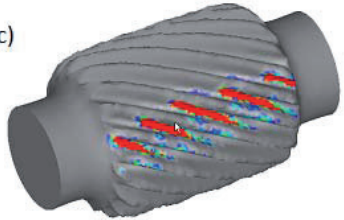

d)

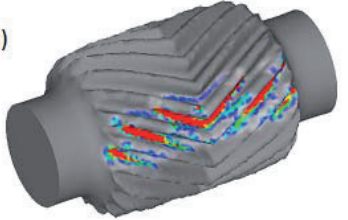

Fig. 9: Strain rate distributions (in l/s) on workpiece surfaces (at the beginning of sizing) during the rolling of a) spur, b) curved, c) helical and d) herringbone gear teeth.
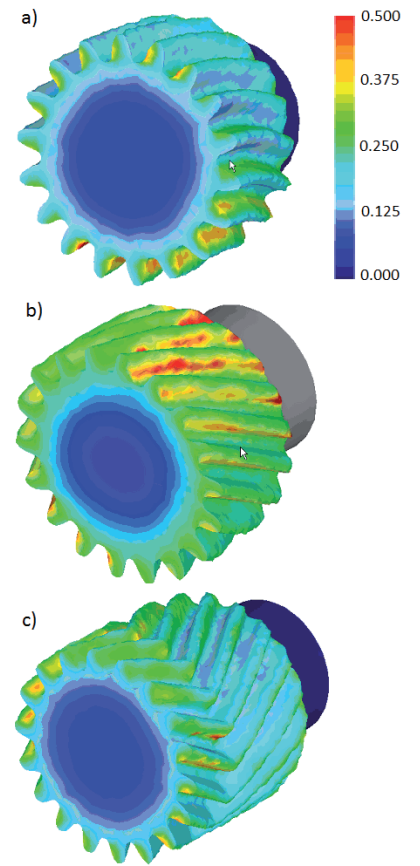

Fig. 10: Distribution of the damage criterion ac $\neg$ cording to CockroftLatham in shafts with a) curved, b) helical and c) herringbone gear teeth. 
It can be stated then that the type of gear teeth being formed does not affect the probability of cracking in the zone of the teeth being formed.

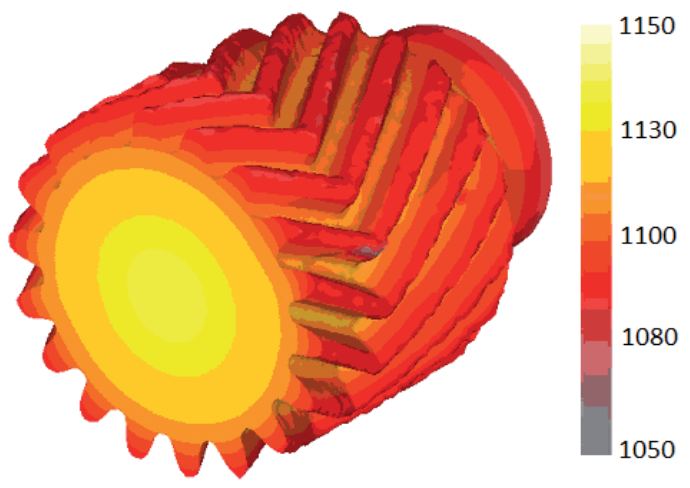

Fig. 11: Temperature distributions (in ${ }^{\circ} \mathrm{C}$ ) in a shaft directly after the process of rolling of her-ringbone gear teeth; billet temperature $1150^{\circ} \mathrm{C}$.

The results of FEM calculations done under the conditions of 3D state of strain confirmed the observations made on the basis of plane strain analysis, according to which, during the forming process, metal cools only in the area of the gear teeth being formed. As Fig. 11 shows, the decrease in metal temperature in this part of the forging is about $50-70^{\circ} \mathrm{C}$ and does not pose a ha-zard to the rolling process. The temperature of the plastically non worked core of the part remains at the initial level of $-1150^{\circ} \mathrm{C}$.

\subsection{An example of CWR of a toothed shaft}

To show the course of the CWR process for manufacturing a toothed shaft, a numerical experiment was carried out, in which the manufacturing process developed in this study was simulated. In the first stage of the process, a stepped shaft was rolled (dimensions

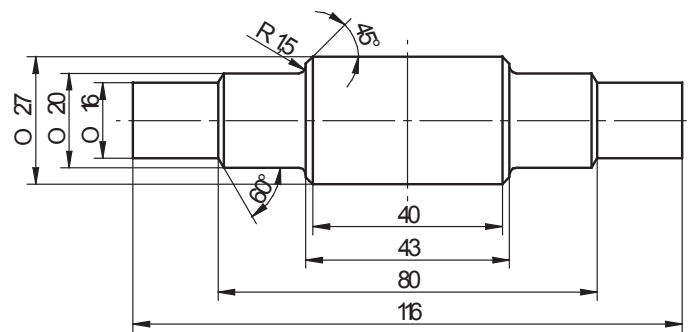

Fig. 12: Shape and dimensions of a stepped shaft rolled in the first stage of the forming process (the diameter of the largest, central step equals the pitch diameter of the gear teeth to be formed in the second stage of the process) shown in Fig. 12) in a way typical of CWR. Next, on the step with the largest diameter, helical teeth were rolled (module 1.5, number of teeth $z=18$ ) by means of inserts (rack bars) with parameters as in Fig. 3. In the last

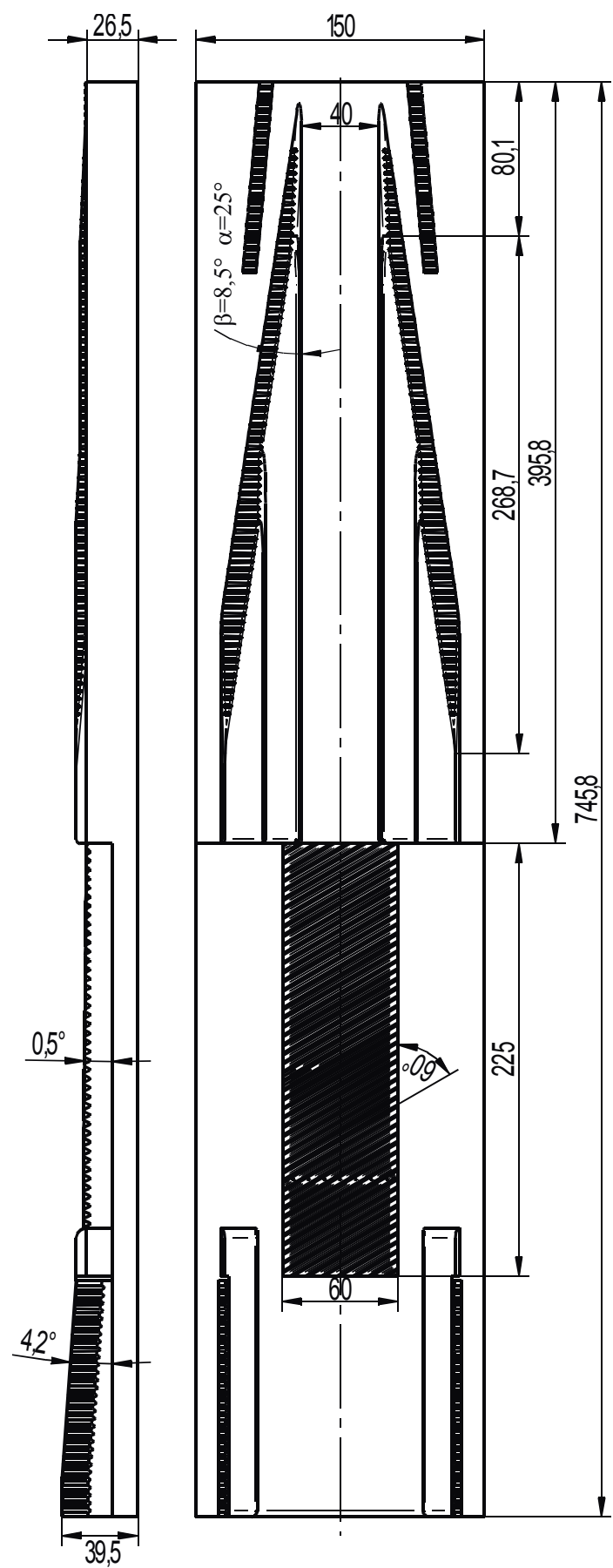

Fig. 13: A tool segment for the manufacturing of toothed shaft forging 
stage of the process, waste with head funnels (formed as a result of surface material flow) was cut off. The tool supporting the process of rolling a toothed shaft according to the proposed concept is shown in Fig. 13. The most important dimensions are also provided in this figure.

Numerical calculations of the toothed shaft rolling process were made using DEFORM-3D software. It was assumed that the rolling billet was a $\varnothing 26.5 \times 90 \mathrm{~mm}$ cylinder. The remaining parame-ters of the process were as in previous section.

Figure 14 shows changes occurring during the forming process in the shape and temperature of a toothed shaft rolled from a billet heated to $1150^{\circ} \mathrm{C}$.

On the basis of the calculations, it can be unequivocally stated that the application of the proposed metal forming method enables rolling of stepped shafts with cylindrical teeth. It was observed, at the same time, that during gear tooth forming the billet was moved in the longitudinal (axial) direction. Because of that, after waste cut-ting, the external steps of the shaft had a length different from the assumed one. However, this fault can be easily eliminated by reversing the or-der of the last two stages of the process, i.e. the waste at the ends should be cut off first and only later should the teeth be rolled.

As far as the temperature of the forging is concerned, it can be stated that although the time of forming $(t=7.5 \mathrm{~s})$ is rather long, the temperature remains within a range appropriate for hot plastic forming of metals. Temperature drops were mainly observed in the area of contact between metal and tools. However, the tool-metal contact in the analyzed process is cyclical. This makes possible leveling out the temperatures on the surface, instead of transmitting the heat from areas of higher temperature to areas of lower temperature. Moreover, considerable amounts of heat are generated (mainly in the contact area) as a result of a change from plastic deformation and friction work.

Figure 15 shows the distribution of effective strain on the surface of a rolled part. From the data provided in this figure, it follows that strains increase together with an increase in the reduction ratio and assume the largest values for shaft steps of smallest diameter. At the same time, it was found that the metal in the external steps of the shaft was plastically worked in its entire volume.

However, during the forming of gear teeth on the central shaft step, material flow had a surface character. This translated into the distribution of the strains, which in this part of the forging were arranged concentrically, and were the largest in the near-surface layers and the smallest in the axis.

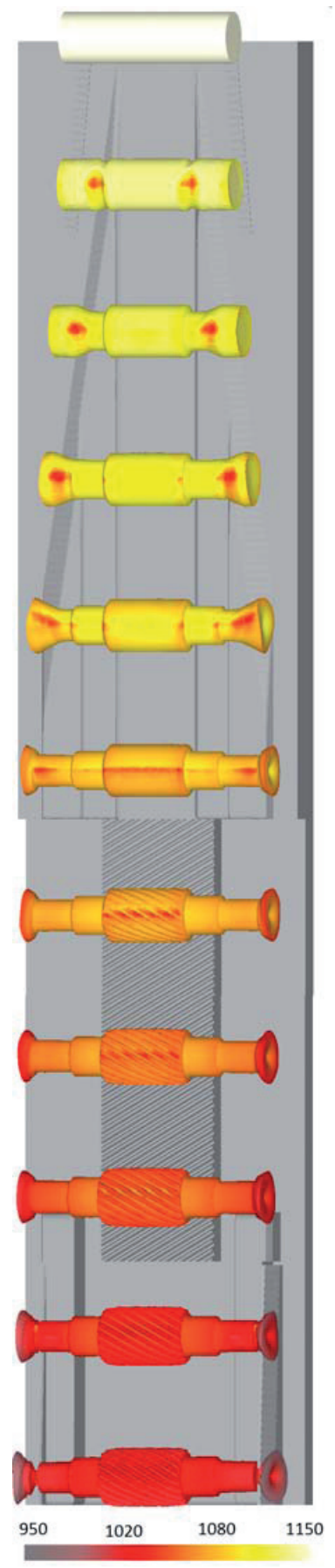

Fig. 13: Changes in the shape of a workpiece (with temperature distribution in ${ }^{\circ} \mathrm{C}$ indicated on color scale) rolled with the flat tools shown in Fig. 13 


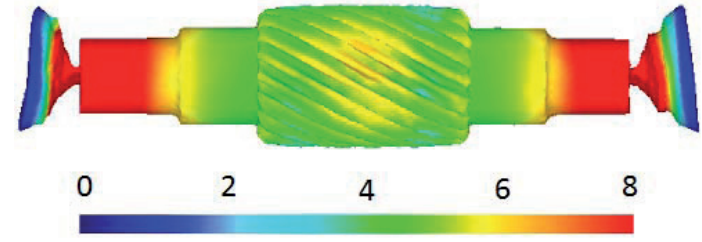

Fig. 15: Effective strain distribution on the surface of a toothed shaft forging.

\section{Laboratory tests}

Laboratory tests were carried out to conclusively confirm the possibility of forming toothed shafts by the proposed method. These tests were made using the flat wedge laboratory rolling mill LUW-2 described in work (Pater, 2007) and available at the Lublin University of Technology. The geometrical parameters of tools and billet were identical to those adopted in the numerical analysis. For economic reasons, the experimental tests were limited to straightcut tooth rolling.

The rolling tests of a toothed shaft were conducted using rack bar-shaped tools Fig. 16. On the basis of these tests, it was established that it was possible to form toothed shafts by means of the proposed CWR method Fig. 17. The results of the experimental studies (regarding the shape of the obtained forgings) were in very good agreement with the results of the numerical calculations. What is more, in destructive tests (consisting in exposing the cross sections), the metal showed no signs of internal crack formation.

During the experimental tests, the forming forces were also registered. Fig. 18 shows the distribution of the tangent force (pressing down the wedge) measured during the rolling of a toothed shaft according to the proposed concept. Additionally, this figure presents the distribution of this force as calculated on the basis of the numerical simulation. A comparison of the distributions of the forces shows that they had a similar course; however the considerable fluctuation of the forces made practical quantitative evaluation impossible. That is why it was more feasible to compare the calculated and the measured work done by the tool (rack bar) during rolling. The values of that work were $865 \mathrm{~J}$ and $1010 \mathrm{~J}$, respectively. This means that the difference recorded in the calculations was about $14.3 \%$, which, for such a complex process as gear tooth rolling, is a satisfactory value, confirming the validity of the numerical analyses.

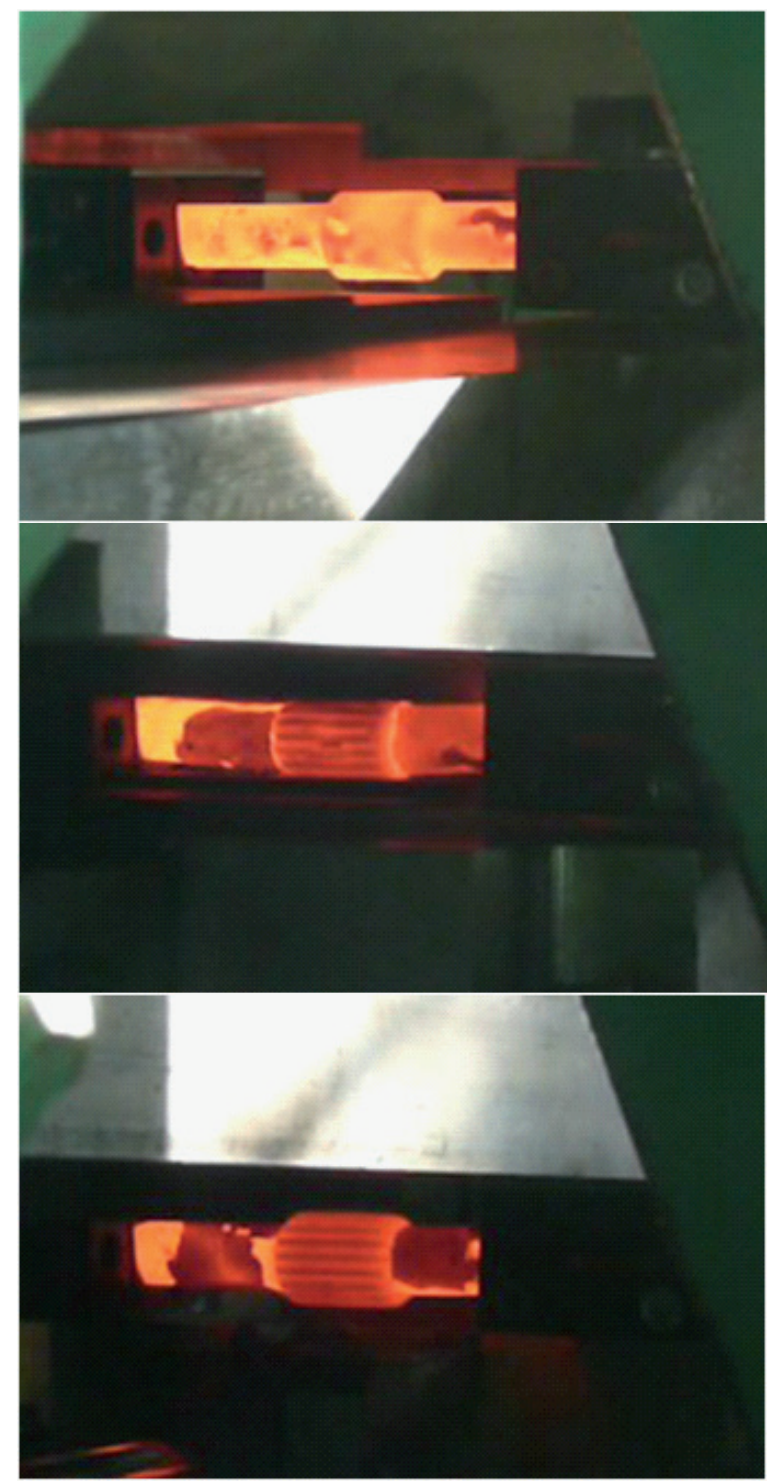

Fig. 16: The course of the process of rolling of a toothed shaft performed in a laboratory of the Lublin University of Technology.

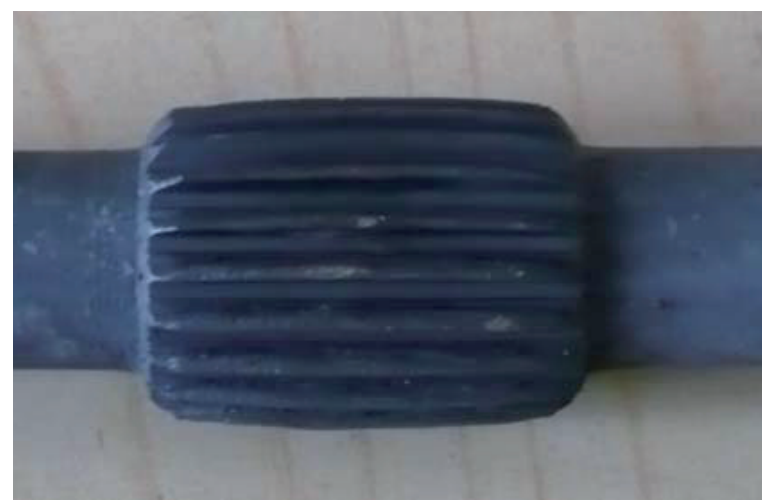

Fig. 17: A toothed shaft obtained in the rolling tests. 


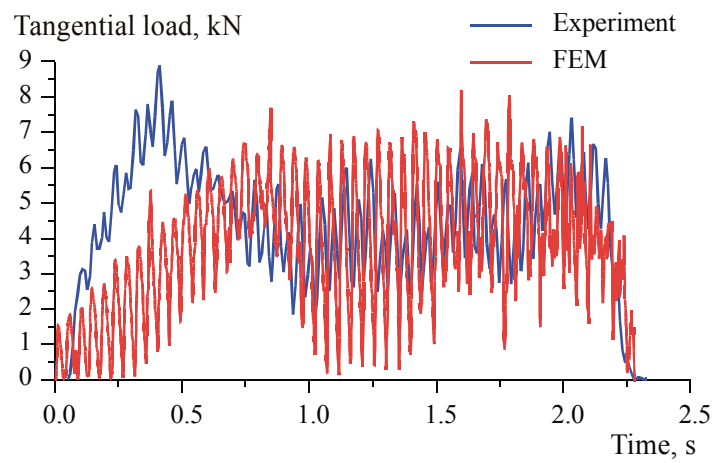

Fig. 17: A comparison of the distributions of tangent force measured and calculated numerically in the process of rolling a toothed shaft with normal teeth (Pater et al., 2007).

\section{Conclusions}

The numerical calculations and experimental tests conducted in this study are the basis for formulating the following conclusions:

- Hot cross-wedge rolling enables formation of stepped shafts with spur, helical, curved and herringbone teeth;

- The tools for gear tooth rolling (flat rack bars) should be made assuming that the lead angle $\gamma$ of the working surface in the forming zone does not exceed $0.5^{\circ}$;

- During gear tooth forming, metal flows on the surface, as a result of which the largest strains occur in the external layers and the smallest in the central (axial) area of the shaft;

Rolling of helical, herringbone, and curved teeth runs more smoothly than spur-tooth rolling;

- The probability of metal cracking during rolling is very small and does not depend on the type of teeth being formed;

- The decrease in the temperature of metal during gear tooth rolling is insignificant and does not pose a threat to the realization of the process.

\section{References}

Lange K. et al. Handbook of Metal Forming. Mc Graw-Hill Book Company 1985

Fu X. P. and T. A. Dean. Past developments, current applications and trends in the cross wedge rolling process. International Journal of Machinery Tools Manufacture Design, Research and Application 1993 vol. 33, pp. 367-400

Pater Z. A study of cross wedge rolling process. Journal of Materials Processing Technology 1998, vol. 80-81 pp. 370-375

Pater Z. Cross-wedge rolling. Ed. Lublin University of Technology 2009 (in Polish)
Pater Z. and J. Tomczak. Cross-wedge rolling of parts with non-circular cross section. Proceedings of the 24th International Manufacturing Conference, IMC 24, Waterford Institute of Technology, Ireland, 2007, pp. 1079-1086

Holub J. Transverse hot rolling. Machinery 16 January 1963, pp. 129133 